\title{
The ErbB4 Ligand Neuregulin-4 Protects against Experimental Necrotizing Enterocolitis
}

Steven J. McElroy, ${ }^{\star}$ Shannon L. Castle, ${ }^{\dagger}$ Jessica K. Bernard, ${ }^{\dagger}$ Dana Almohazey, ${ }^{\ddagger}$ Catherine J. Hunter ${ }^{\S}$ Brandon A. Bell, ${ }^{\dagger}$ Denise Al Alam, ${ }^{\dagger}$ Larry Wang, ${ }^{\top}$ Henri R. Ford, ${ }^{\dagger}$ and Mark R. Frey ${ }^{\ddagger}$

From the Division of Neonatology, * Department of Pediatrics, University of Iowa, Iowa City, Iowa; the Division of Pediatric Surgery, ${ }^{\dagger}$ Department of Surgery, and the Departments of Pathology" and Biochemistry and Molecular Biology, "University of Southern California Keck School of Medicine, Los Angeles, California; the Department of Pediatrics, ${ }^{\ddagger}$ University of Southern California Keck School of Medicine and The Saban Research Institute at Children’s Hospital Los Angeles, Los Angeles, California; and the Departments of Surgery and Pediatrics, ${ }^{\S}$ Ann and Robert H. Lurie Children's Hospital, Northwestern University, Chicago, Illinois

Accepted for publication

June 13, 2014.

Address correspondence to Mark R. Frey, Ph.D., The Saban Research Institute at Children's Hospital Los Angeles, 4650 Sunset Blvd., MS\#137, Los Angeles, CA 90027. E-mail: mfrey@chla.usc.edu.

\begin{abstract}
Necrotizing enterocolitis (NEC) affects up to $10 \%$ of premature infants, has a mortality of $30 \%$, and can leave surviving patients with significant morbidity. Neuregulin-4 (NRG4) is an ErbB4-specific ligand that promotes epithelial cell survival. Thus, this pathway could be protective in diseases such as NEC, in which epithelial cell death is a major pathologic feature. We sought to determine whether NRG4-ErbB4 signaling is protective in experimental NEC. NRG4 was used i) in the newborn rat formula feeding/ hypoxia model; ii) in a recently developed model in which 14- to 16-day-old mice are injected with dithizone to induce Paneth cell loss, followed by Klebsiella pneumoniae infection to induce intestinal injury; and iii) in bacterially infected IEC- 6 cells in vitro. NRG4 reduced NEC incidence and severity in the formula feed/hypoxia rat model. It also reduced Paneth cell ablation-induced NEC and prevented dithizone-induced Paneth cell loss in mice. In vitro, cultured $\mathrm{ErbB4}^{-/-}$ileal epithelial enteroids had reduced Paneth cell markers and were highly sensitive to inflammatory cytokines. Furthermore, NRG4 blocked, through a Src-dependent pathway, Cronobacter muytjensii-induced IEC- 6 cell apoptosis. The potential clinical relevance of these findings was demonstrated by the observation that NRG4 and its receptor ErbB4 are present in human breast milk and developing human intestine, respectively. Thus, NRG4-ErbB4 signaling may be a novel pathway for therapeutic intervention or prevention in NEC. (Am J Pathol 2014, 184: 2768-2778; http://dx.doi.org/10.1016/j.ajpath.2014.06.015)
\end{abstract}

Necrotizing enterocolitis (NEC) is a devastating intestinal disease primarily affecting premature infants. In the United States, NEC afflicts $7 \%$ of infants weighing $<1500$ g. ${ }^{1}$ In addition to prematurity, risk factors include hypoxia, bacterial colonization of the intestine, and formula feeding. ${ }^{2}$ The development of NEC seems to be multifactorial, and patients may have any combination of risk factors at the time of presentation. The current disease model is that the immature gut barrier, along with defects in endogenous antimicrobial activity, ${ }^{3}$ allows bacterial translocation across the epithelium, triggering an inflammatory response that further worsens gut barrier function. Pathogenic bacteria, ${ }^{4,5}$ inflammatory cytokines such as tumor necrosis factor (TNF), ${ }^{6-8}$ and Paneth cell dropout ${ }^{3}$ have all been associated with human NEC and contribute to NEC-like injury in animal models.
Available therapy for either prevention or treatment of NEC is limited, and patients currently face a mortality rate of approximately $30 \% .^{9-11}$ Breast-fed infants have a lower risk of NEC than their formula-fed peers, ${ }^{12,13}$ and a variety of studies have attempted to identify and characterize factors in human milk that confer this protection. Candidate protective molecules to date include immunoglobulins, oligosaccharides, lactoferrin, and soluble growth factors, such as

Supported by NIH grants R01DK095004 (M.R.F.), K01DK077956 (M.R.F.), R03DK090295 (M.R.F.), K08DK083677 (S.J.M.), R03DK097335 (S.J.M.), and R01AI014032 (H.R.F.); by Senior Research Award 3791 from the Crohn's and Colitis Foundation of America (M.R.F.); and by a Research Career Development Award from The Saban Research Institute (M.R.F.).

S.J.M. and S.L.C. contributed equally to this work.

Disclosure: M.R.F. has a patent application pending on the possible therapeutic use of NRG4 in intestinal inflammation. 
epidermal growth factor (EGF) ${ }^{14}$ and heparin-binding EGFlike growth factor (HB-EGF) ${ }^{15}$ In rat and mouse models, enteral administration of either $\mathrm{EGF}^{16,17}$ or $\mathrm{HB}^{-\mathrm{EGF}^{18}}$ decreases the incidence and severity of NEC. The primary receptor for both EGF and HB-EGF is EGF receptor (EGFR), the prototypic member of the ErbB receptor tyrosine kinase family. However, HB-EGF also activates ErbB4, a member of the ErbB family whose potential role in the developing gut and NEC is not known.

ErbB4 has unique biochemical properties distinguishing it from other ErbB family members. Compared with EGFR, ErbB2, or ErbB3, it recognizes a broader collection of ligands, including the EGF-like growth factors HB-EGF and betacellulin as well as the heregulin/neuregulin molecules. ${ }^{19}$ At the same time, the ErbB4 c-terminus contains a distinct and somewhat restricted set of functional docking sites for downstream effectors ${ }^{20}$ and is thus predicted to elicit divergent cellular effects on activation versus other family members. In fact, we recently demonstrated that neuregulin-4 (NRG4), an ErbB4-specific ligand that does not bind or activate other family members, including EGFR, ${ }^{21}$ specifically promotes survival but not migration or proliferation of mouse colon epithelial cells. ${ }^{22}$ Thus, ErbB4 is a potentially unique and selective target for therapeutic protection in diseases in which intestinal epithelial cell death is a major pathologic feature.

We previously reported that ErbB4 is up-regulated in adult human and murine colon inflammation in vivo ${ }^{23}$ and that ErbB4 overexpression protects cultured colonocytes from cytokine-induced apoptosis in a ligand-dependent manner. ${ }^{24}$ Furthermore, i.p. NRG4 administration reduces the severity of acute murine dextran sulfate sodium colitis. ${ }^{22}$ Thus, it seems that ErbB4 induction is a natural compensatory response meant to preserve the epithelium rather than part of disease pathology and that ErbB4 activation with exogenous ligand is protective against induced inflammation. However, the role of this signaling pathway in the small intestine, or during development, has not been described. We hypothesized that ErbB4 and its ligands have a protective role in the small bowel during postnatal development, particularly in the setting of NEC-associated acute injury and inflammation. To advance our understanding of ErbB4 biology in intestinal homeostasis and disease, we tested the hypothesis that NRG4-ErbB4 signaling is protective in experimental NEC.

\section{Materials and Methods}

\section{Ethics Statement, Recruitment, and Sample Collection}

For the animal experiments, all the studies were approved and monitored by the Institutional Animal Care and Use and Biosafety committees of Children's Hospital Los Angeles (Vertebrate Animals Welfare Assurance No. A3276-01) or the University of Iowa (Vertebrate Animals Welfare Assurance No. A3021-01), as appropriate, and were performed in strict accordance with the recommendations in the Guide for the Care and Use of Laboratory Animals. ${ }^{25}$ For the study of human milk, the Committee on Clinical Investigations (Institutional Review Board for research ethics) of Children's Hospital Los Angeles reviewed and approved the entire study, including recruitment and consenting practices, before the recruitment of study participants and the collection of samples.

Recruitment flyers were placed in the hospital day care, and potential participants contacted researchers by telephone if they were interested in donating. Participants were given a study information sheet and were allowed to review this information at home before milk donation. Because the study represented negligible risk and no identifying information was collected, verbal consent was obtained from participants at the time of donation to minimize the participant paperwork burden.

Consent, date, and volume of donation were recorded in the collecting researcher's notebook. No participant information was recorded; milk samples were labeled only with the date of collection and were placed in frozen storage. For human NEC specimens, after Institutional Review Board approval and parental consent were obtained, human tissue samples were collected from infants undergoing bowel resection at the Ann and Robert H. Lurie Children's Hospital (Chicago, IL). Clinically indicated specimens were removed. No additional samples were taken for the purposes of this study, and neither did study participants incur additional surgical risk. The type of tissue obtained, the reason for surgery, and the corrected gestational age were recorded.

The intestinal samples were categorized into one of three groups: active NEC (intestine removed during surgery for perforation and sepsis), a history of NEC with ongoing complications (eg, intestine removed after a history of NEC due to sequelae of illness, such as NEC stricture), or a history of NEC but no current disease (eg, ostomy takedown, $\geq 12$ weeks after NEC). Tissue was collected, divided into parts, and fixed and processed into paraffin blocks or preserved in Allprotect reagent (Qiagen Inc., Valencia, CA) and stored at $-80^{\circ} \mathrm{C}$ before protein isolation for Western blot analysis.

\section{Formula Feeding/Hypoxia Rat Model of NEC}

NEC was induced in newborn rats by formula feeding/hypoxia (FFH) as previously described. ${ }^{26}$ Newborn Sprague-Dawley rats (Harlan Laboratories, Indianapolis, IN) delivered at term were immediately separated from the mothers into one of three treatment groups: i) kept with mothers and breast-fed; ii) fed thrice daily by gavage of $0.2 \mathrm{~mL}$ of clean formula consisting of $15 \mathrm{~g}$ of Similac 60/40 (Abbott Nutritional, Columbus, $\mathrm{OH}$ ) in $75 \mathrm{~mL}$ of Esbilac canine milk replacement (PetAg Inc., Hampshire, IL) with three times (10 minutes each) daily hypoxia exposure with $5 \% \mathrm{O}_{2}$ and $95 \% \mathrm{~N}_{2}$ and with $200 \mathrm{ng}$ per feed of recombinant NRG4 (saturating dose in a formula feed for ErbB4 phosphorylation, as defined by a concentration curve of 25 to $250 \mathrm{ng}$ administered followed by Western blot analysis for phospho-ErbB4 on ileal homogenates; data not 
shown) added to the formula; or iii) same as group ii) but with an equal volume $(2 \mu \mathrm{L})$ of phosphate-buffered saline vehicle instead of NRG4 added to formula.

Animals were examined frequently and were euthanized if signs of severe distress were noted. On day 4 ( 84 hours after birth), rats were euthanized. Tissue was fixed, paraffin embedded, and hematoxylin and eosin stained. Morphologic changes in the intestinal epithelium were graded microscopically, by a pathologist blinded to groups, from grade 0 (normal) to grade 4 (severe) based on pathologic manifestations, including submucosal edema, epithelial sloughing/obliteration, neutrophil infiltration, intestinal perforation, epithelial separation from submucosa, and necrosis.

\section{Dithizone/Klebsiella Mouse Model of NEC}

CD-1 mice (14 to 16 days old) were separated from their mothers and maintained without feeds in a temperature- and humidity-controlled chamber throughout the experiment and then were subjected to an experimental NEC protocol as previously described. ${ }^{27}$ Pups were given $75 \mathrm{mg} / \mathrm{kg}$ of the zinc chelator dithizone (Sigma-Aldrich, St. Louis, MO) or an equivalent volume of lithium carbonate vehicle alone as control by i.p. injection. This ablates Paneth cells, which are highly sensitive to zinc levels. ${ }^{28}$ Dithizone was given with $250 \mu \mathrm{g} / \mathrm{kg}$ NRG4 (saturating dose for ErbB4 phosphorylation as determined by a concentration curve of 31.25 to 500 $\mu \mathrm{g} / \mathrm{kg}$ administered i.p. followed by Western blot analysis for phospho-ErbB4 on ileal mucosal scrapings; data not shown) or an equivalent volume of phosphate-buffered saline vehicle alone. Six hours after injection, mice were enterally infected by gastric gavage with $1 \times 10^{11} \mathrm{CFU} / \mathrm{kg}$ Klebsiella pneumoniae (ATCC, Manassas, VA) or were given a gavage of an equivalent volume of sterile media (nutrient broth; ATCC). Mice were monitored for 10 hours after gavage and then were sacrificed for analysis. Mucosal injury was evaluated by a single blinded investigator and was graded on a 5-point scale: grade 0 , no injury; grade 1 , mild separation of lamina propria; grade 2, moderate separation of submucosa; grade 3, severe separation and/or edema in submucosa; and grade 4 , transmural injury.

\section{Intestinal Enteroid Cultures}

Intestinal crypts were isolated from intestines of young adult (6- to 8-week-old) ErbB4 ${ }^{\text {flox/flox }}$ and ErbB4 ${ }^{\text {flox/flox }}$;Villin-Cre mice $^{29}$ by calcium chelation $(2 \mathrm{mmol} / \mathrm{L}$ EDTA in phosphate-buffered saline) and mechanical agitation (2 minutes of shaking by hand in phosphate-buffered saline containing $43.3 \mathrm{mmol} / \mathrm{L}$ sucrose and $54.9 \mathrm{mmol} / \mathrm{L}$ sorbitol) and then were embedded in Matrigel (BD Biosciences, Franklin Lakes, NJ) containing $50 \mathrm{ng} / \mathrm{mL}$ of EGF, $100 \mathrm{ng} /$ $\mathrm{mL}$ of Noggin, and $500 \mathrm{ng} / \mathrm{mL}$ of R-spondin. Cultured crypts were established as enteroids essentially as previously described $^{30}$ and were passaged once before being used in experiments.

\section{Bacteria and Cell Lines}

Cronobacter muytjensii (ATCC 51329; formerly known as Cronobacter or Enterobacter sakazakii ${ }^{31}$ ) and IEC-6 rat ileal epithelial cells were obtained from ATCC. Bacteria were grown in tryptic soy broth. IEC-6 cells (passages 20 to 26) were maintained in Dulbecco's modified Eagle's medium supplemented with $10 \%$ fetal calf serum, $100 \mathrm{U} / \mathrm{mL}$ of penicillin G, and $100 \mathrm{U} / \mathrm{L}$ of streptomycin C. Twenty-four hours before the experiments, the cells were washed and then resupplied with medium containing no antibiotics.

\section{Apoptosis Assays}

Rates of apoptosis on histologic specimens were determined by in situ oligo ligation DNA fragmentation assay (EMD Millipore, Billerica, MA), as we have previously done. ${ }^{22}$ Relative apoptosis in IEC-6 cells was measured by adding a luminescent caspase substrate (Caspase-Glo 3/7; Promega Corp., Madison, WI) to cultures, then determining luminescence with a Victor $^{3}$ multilabel plate reader (PerkinElmer, Waltham, MA) after 60 minutes.

\section{Cell Migration}

Restitution (migration) assays were performed using a drill press wound assay as previously described. ${ }^{22}$ Briefly, a drill-mounted rotating silicone tip was used to make multiple approximately $1.5 \mathrm{~mm}^{2}$ wounds in confluent IEC-6 cultures. Wounds were photographed over time, area was determined using ImageJ software version $1.49 \mathrm{~d}(\mathrm{NIH}$, Bethesda, MD), and percentage closure was determined.

\section{Cell Proliferation}

IEC-6 cultures were serum deprived $(0.5 \%$ fetal bovine serum) for 48 hours and then were stimulated with growth factors for 24 hours. Cultures were labeled with 5-ethynyl2 -deoxyuridine (EdU) for the last 2 hours of incubation and were fixed. Percentage of EdU-labeled cells was determined using a Click-iT EdU proliferation kit (Life Technologies, Grand Island, NY).

\section{Antibodies, Growth Factors, and Inhibitors}

The antibodies used were polyclonal anti-ErbB4 (c-18) (Santa Cruz Biotechnology, Santa Cruz, CA); anti-Src, antiphospho-Tyr416-Src, and anti-phospho-Tyr1284-ErbB4 (Cell Signaling Technology Inc., Danvers, MA); anti-actin (Sigma-Aldrich); IRDye-conjugated secondary antibodies (Li-Cor Biosciences, Lincoln, NE); and Alexa Fluor 555-conjugated anti-rabbit (Invitrogen, Carlsbad, CA). Recombinant HRG, Noggin, and R-spondin were purchased from R\&D Systems (Minneapolis, MN), EGF from PeproTech (Rocky Hill, NJ), and NRG4 from Reprokine Ltd. 
(Valley Cottage, NY). PP2 was purchased from SigmaAldrich.

\section{Human Breast Milk}

Breast milk was obtained from healthy volunteers. Milk was collected in standard lactation bags, deidentified, and frozen at $-70^{\circ} \mathrm{C}$. Samples were defrosted and centrifuged at 14,000 rpm for 15 minutes to remove the lipid layer. The remaining protein layers were resuspended, mixed, and solubilized in Laemmli buffer for Western blot analysis.

\section{Statistical Analysis}

Data were analyzed by analysis of variance using the Tukey post-test, $U$-test, or Kruskal-Wallis test, as appropriate.

\section{Results}

\section{NRG4 Reduces Incidence and Injury in a Rat Model of NEC}

ErbB4 expression is induced by injury and inflammation in the adult colon ${ }^{23}$ as a compensatory response to damage, and NRG4 reduces TNF-induced apoptosis in the adult mouse colon. ${ }^{22}$ To test whether ErbB4 activation is protective in the developing small intestine, we used the well-established FFH model of rat NEC. In this highly penetrant model, ${ }^{18,26}$ the combination of hypertonic formula feeding combined with hypoxia produces a clinical picture and histologic features similar to human NEC. FFH pups had extensive epithelial damage, whereas pups given NRG4 to activate ErbB4 (FFH/ NRG4) had histologic features similar to those of dam-fed controls (Figure 1A). Pathologic scoring identified a significant protective effect, with mean \pm SD damage scores of $1.50 \pm 0.23$ in FFH pups and $0.69 \pm 0.21$ in the FFH/NRG4 group (Figure 1B). FFH/NRG4 pups had a reduced incidence of disease, defined as the percentage of animals with histologic damage scores $\geq 2$ at sacrifice on day 4 (15\% in FFH/ NRG4 versus $43 \%$ in FFH). The number of apoptotic cells in the remaining epithelial villi was also markedly reduced in NRG4-treated animals (Figure 1C). Because inflammation during development may not be the same as in adult disease, we also tested whether injury-associated ErbB4 induction occurs in experimental NEC. Immunostaining for ErbB4 showed an increase in receptor expression in FFH versus dam-fed pups (Figure 1D).

\section{NRG4 Blocks Experimental NEC Induced by Dithizone/ Klebsiella in Mice}

To test NRG4-ErbB4 signaling in a second model of NEC, we used the recently described dithizone/Klebsiella (DK) model $^{27}$ in 2-week-old mice. In this approach, Paneth cells are ablated by dithizone injection (which chelates zinc required by Paneth

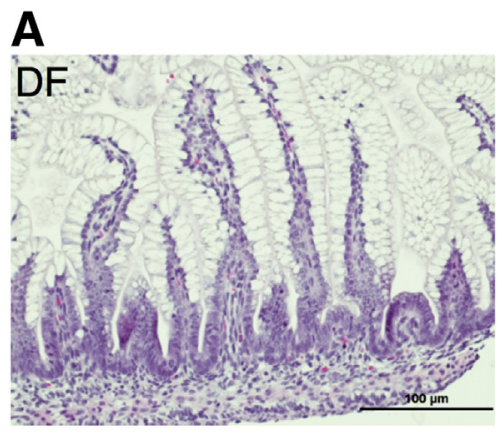

B

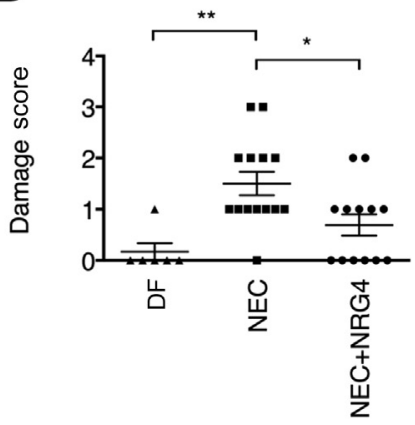

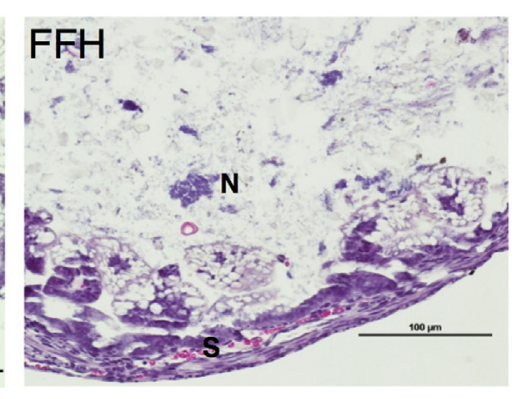

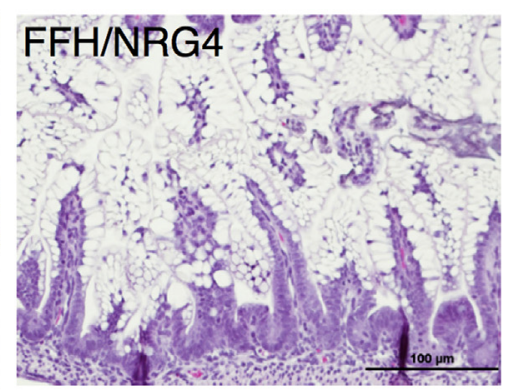

C

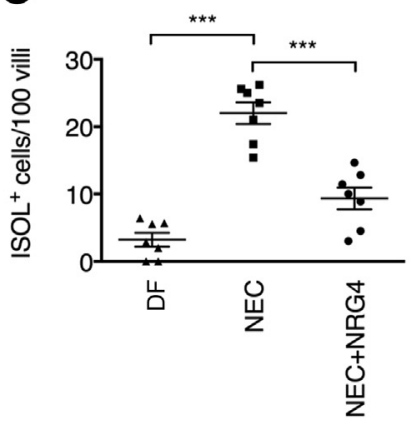

D

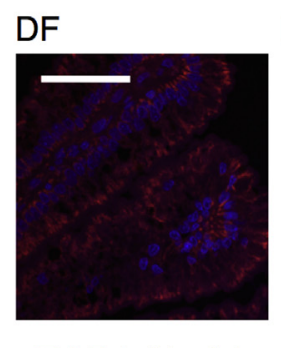

ErbB4 Nuclei

Figure 1 Experimental NEC severity is reduced in rat pups given NRG4. A: Hematoxylin and eosin-stained sections of ileums from control [dam-fed (DF)], $\mathrm{FFH}$, and FFH/NRG4 rat pups at sacrifice on day 4 after birth. B: Damage scores. Specimens were scored by an investigator masked to experimental conditions. C: Tissue was subjected to in situ oligo ligation (ISOL) stain to detect apoptotic cells, and positive cells per 100 villi were counted. D: Sections of DF and FFH intestinal tissue were subjected to immunofluorescence analysis for ErbB4. IgG-negative controls (not shown) had no detectable staining. $n=6$ DF, 14 FFH, and $13 \mathrm{FFH} / \mathrm{NRG} 4$ pups in three independent experiments. ${ }^{*} P<0.05,{ }^{*} P<0.01$, and ${ }^{*} * *<0.001$. Each point represents one animal. Lines show means \pm SEM. Scale bars: $100 \mu \mathrm{m}$. N, necrotic region; S, areas of separation from the basement membrane. 
A

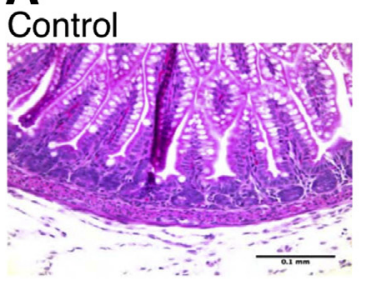

DK

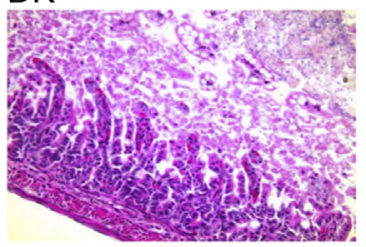

NRG4

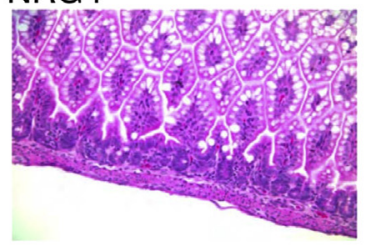

DK+NRG4

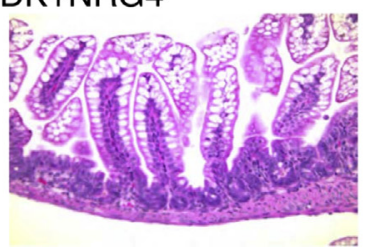

B

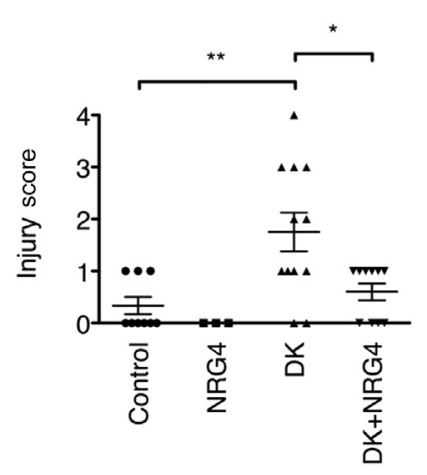

C IHC: ErbB4

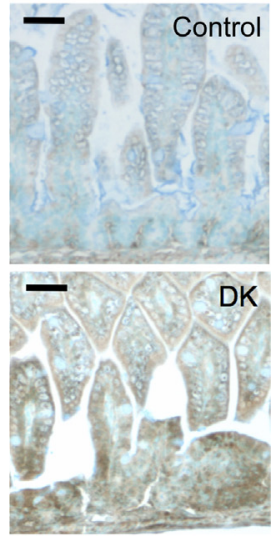

Figure 2 NRG4 protects mice from DK-induced experimental NEC. Fourteen-day-old mice were injected with dithizone or vehicle, with or without NRG4, and were gavaged with $K$. pneumoniae or vehicle after 6 hours. Ten hours after gavage, mice were sacrificed and ileums were fixed and sectioned for hematoxylin and eosin staining (A) and histologic scoring (B). C: Sections of control and DK intestinal tissue were subjected to immunohistochemical (IHC) analysis for ErbB4. IgG-negative controls (not shown) had no detectable staining. $n=9$ control, 6 NRG4, 12 DK, and 10 DK/NRG4 mice in three independent experiments. ${ }^{*} P<0.05,{ }^{* *} P<0.01$. Scale bars: $100 \mu \mathrm{m}(\mathbf{A}) ; 50 \mu \mathrm{m}$ (C).

cells), followed 6 hours later by $K$. pneumoniae gavage, resulting in severe NEC-like symptoms within 24 hours (Figure 2A). NRG4 given by i.p. injection simultaneously with dithizone administration was protective in this model, completely blocking DK-induced histologic damage (Figure 2B) (mean \pm SD damage score: $1.75 \pm 0.37$ in DK mice versus $0.6 \pm 0.16$ in DK + NRG4 mice). Similar to the rat model, injury in the DK mice was associated with increased ErbB4 immunostaining (Figure 2C).

\section{Dithizone-Induced Paneth Cell Loss Is Blocked by NRG4}

In the DK model of mouse NEC, dithizone ablates the Paneth cell population and, thus, sensitizes the intestine to
Klebsiella-induced damage. Human NEC has been associated with loss of Paneth cells in the ileum, ${ }^{3}$ suggesting that this part of the model may be especially informative for the development of clinical applications. To test whether ErbB4 signaling is affecting the Paneth cell compartment specifically, we stained ileums from control, DK-, or DK + NRG4-treated mice with Alcian blue/ periodic acid-Schiff stain or by immunohistochemical analysis for lysozyme to identify and count Paneth cells. NRG4 blocked Paneth cell loss in the DK model (Figure 3) (mean \pm SD Paneth cells per crypt: $2.80 \pm 0.26$ control, $1.35 \pm 0.44 \mathrm{DK}, 3.00 \pm 0.25 \mathrm{DK}+$ NRG4), suggesting that protection of this specific population, or of Paneth cell progenitors, may be part of the mechanism of protection against NEC.
A
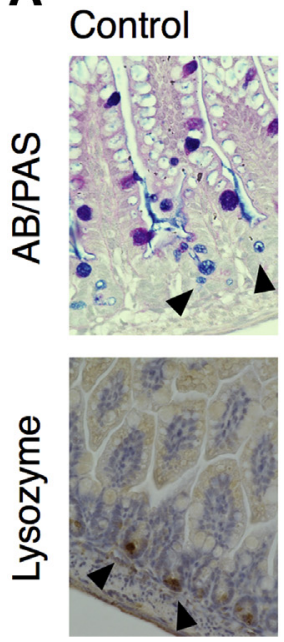
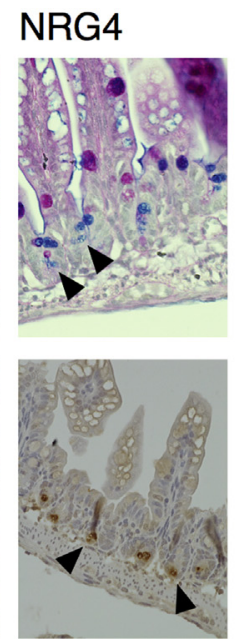

DK
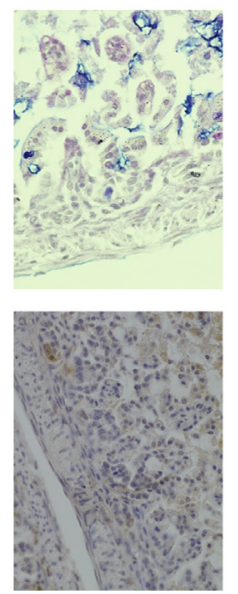
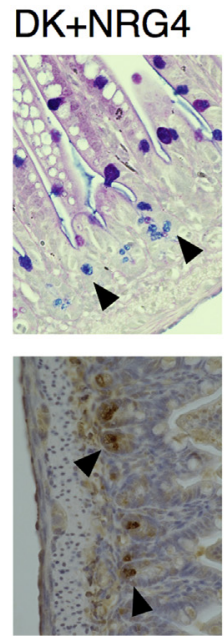

B

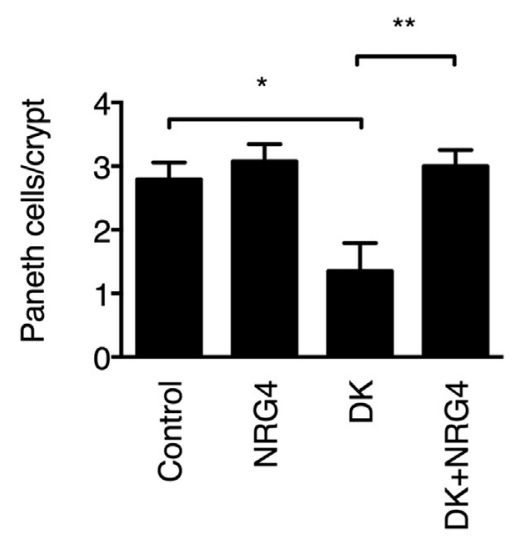

Figure 3 Paneth cell ablation in DK NEC is blocked by NRG4. A: Ileums from 14-day-old mice subjected to DK NEC, with or without NRG4, underwent staining by Alcian blue/periodic acid-Schiff (AB/PAS) and immunohistochemical analysis for lysozyme to identify Paneth cells (arrowheads). B: Paneth cells per crypt from five mice per condition ( $>50$ crypts per mouse) were counted. Data are shown as means $\pm \mathrm{SEM}$. ${ }^{\star} P<0.05,{ }^{* \star} P<0.01$. 
ErbB4-Null Mouse Ileal Enteroids Are Dysmorphic, Have Reduced Paneth Cell Numbers, and Are Highly Sensitive to TNF

To further investigate the role of ErbB4 in Paneth cell and intestinal epithelial maintenance, we used ileal epithelial enteroid cultures $^{32}$ from young adult mice with ErbB4 specifically deleted in their intestinal epithelium $\left(\mathrm{ErbB}_{4}{ }^{\text {flox/flox; }}\right.$; Vil-Cre). In vivo, these mice do not have an overt small intestinal phenotype when unchallenged (data not shown), similar to other growth factor receptors, including $\mathrm{EGFR}^{33}$ and ErbB2. ${ }^{34}$ The lack of phenotype may be due to compensatory signals from epithelial-mesenchymal interaction, so we used the enteroid model to specifically examine epithelial responses. Compared with ErbB4 $4^{\text {flox/flox }}$ controls, ErbB4-null enteroids showed a significant reduction in the Paneth cell marker lysozyme (Figure 4A) and displayed a dysmorphic phenotype (Figure 4B). The loss of lysozyme in knockout enteroids was comparable with that induced in control enteroids exposed to TNF, an inflammatory cytokine implicated in the pathogenesis of NEC. ${ }^{6,7}$ Furthermore, although wild-type enteroids were resistant to TNF challenge (Figure 4B), ErbB4-null cultures challenged with the cytokine underwent a complete loss of architecture, with very few surviving epithelial cells at 4 days (Figure 4B).

\section{Bacterially Induced Small Intestinal Epithelial Cell Apoptosis Is Blocked by NRG4 in Vitro}

To test in vitro the signaling pathways involved in NRG4 protection of the small intestine, we infected IEC-6 rat ileal epithelial cells with $10^{5} \mathrm{CFU} / \mathrm{mL}$ C. muytjensii, a bacterium related to strains associated clinically with NEC. C. muytjensii has been previously used with IEC-6 cells to study NECrelated cell death. ${ }^{5}$ Cultures were exposed to $C$. muytjensii in the presence of vehicle alone or the growth factors EGF (10 ng/ $\mathrm{mL})$, heregulin-1 $\beta(100 \mathrm{ng} / \mathrm{mL})$, or NRG4 (100 ng/mL). After 6 hours, apoptosis was assessed by a luminescent assay for caspases 3 and 7. Similar to previous reports, C. muytjensii rapidly stimulated apoptosis in IEC-6 cells (a mean \pm SD $3.04 \pm 0.15$-fold increase in caspase activity; $P<0.01$ ). All three ErbB receptor ligands inhibited apoptosis compared with bacteria alone (reduction versus bacteria alone: EGF, 28.3\%; HRG, 27.5\%; and NRG4, 41.4\%) (Figure 5A). Unlike EGF, NRG4 had no effect on C. muytjensii inhibition of IEC-6 cell migration in a modified scratch wound assay (Figure 5B); infection reduced IEC- 6 cell migration, and NRG4 was not able to rescue this response. NRG4 also did not induce IEC-6 proliferation (Figure 5C). Thus, NRG4 signaling is specific for survival in this cell model.

\section{Protection against Bacterially Induced Apoptosis Is Reversed by Src Kinase Inhibitor}

Relative to other ErbB family members, ErbB4 has a restricted set of potential binding sites for downstream signaling mediators. ${ }^{20}$ One of the putative interactions is with Src. Because this kinase has been associated with antiapoptotic signaling in the gastrointestinal tract, ${ }^{35,36}$ we asked whether Src inhibition reversed NRG4 protective effects on bacterially challenged IEC-6 cells. Src was phosphorylated on the activation site Tyr416 in response to NRG4 exposure (data not shown), and treatment of cultures with 1 $\mu \mathrm{mol} / \mathrm{L}$ Src inhibitor PP2 completely restored $C$. muytjensiiinduced caspase activity in the presence of NRG4 (Figure 5D). Together, these data show that Src activation is crucial for NRG4-induced blockade of bacterially induced apoptosis in
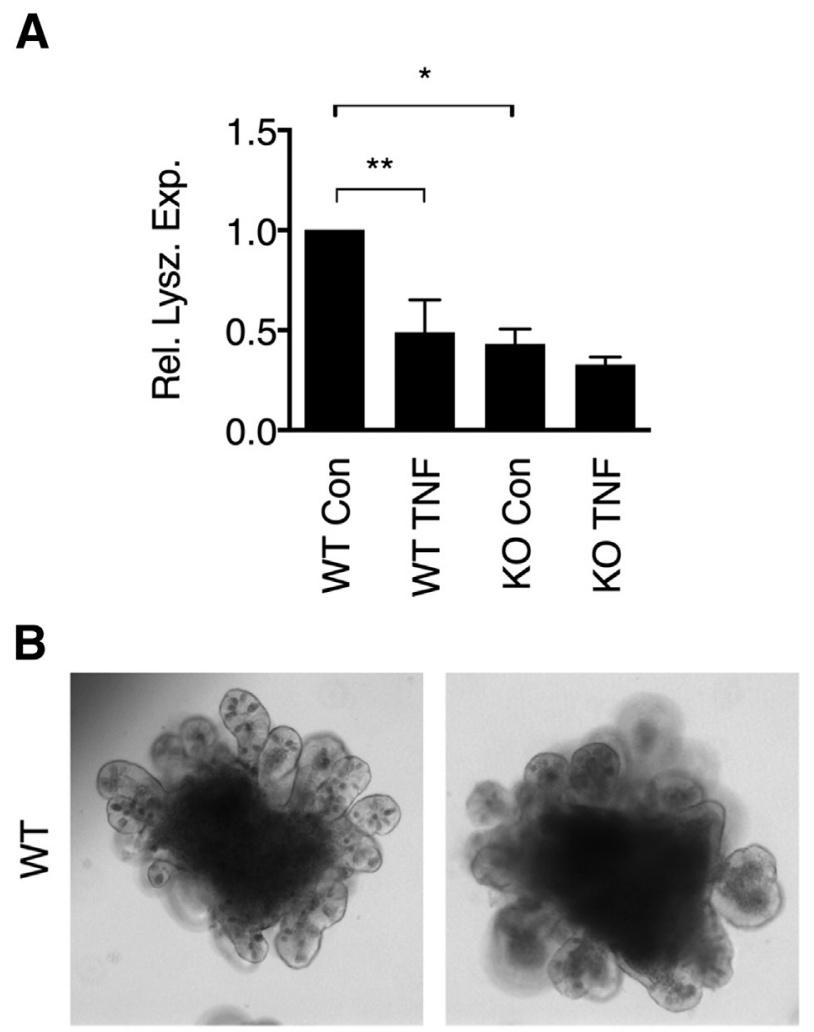

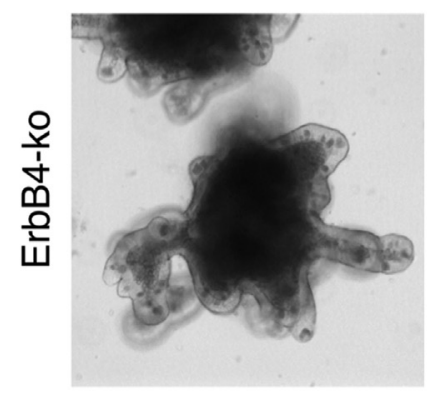

Control

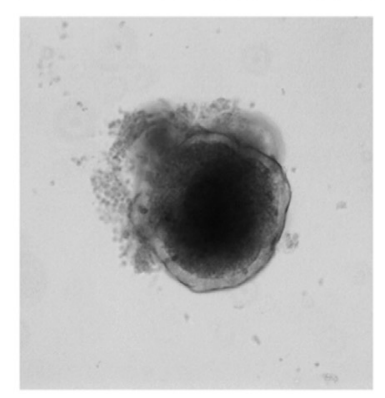

TNF
Figure 4 ErbB4 is necessary for Paneth cell development and intestinal epithelial integrity. A: Ileal enteroids from ErbB ${ }^{\text {flox/flox }}$ (WT) and ErbB4 ${ }^{\text {flox/flox }}$;Vil-Cre (KO) mice were cultured in the presence or absence of $200 \mathrm{ng} / \mathrm{mL}$ of TNF for 4 days. RNA was prepared and analyzed by quantitative PCR for lysozyme expression (Rel. Lysz. Exp.) (reference gene: $G A P D H)$. B: Bright-field microscopy showed representative morphology of WT and KO enteroids with or without TNF exposure. $n=3$ independent experiments with cultures from three mice per genotype. Graphs show means \pm SEM. ${ }^{*} P<0.05,{ }^{*} P<0.01$. Con, control. 
small intestinal epithelial cells. Importantly, Western blot analysis of ileal mucosal scrapings from 14-day-old mice injected with NRG4 shows that this ligand can activate Src signaling in vivo (Figure 5E).

NRG4 Is Present in Human Milk, and ErbB4 Is Present in Human NEC Intestine

As described above (see results from Figure 1), we found that NRG4 supplemented in formula is protective against experimental NEC. To determine whether this represents restoration of a growth factor normally present in breast milk, the whey fractions of human milk from anonymous donors were subjected to Western blot analysis for NRG4. All six specimens analyzed were positive for NRG4 (Figure 6A), whereas none was detected in the formula control. Immunoreactivity was competed off by antigenic blocking peptide, demonstrating binding specificity. Comparison to recombinant NRG4 standard suggested milk contains a mean $\pm \mathrm{SD} 159 \pm 34 \mathrm{ng} / \mathrm{mL}$ of NRG4, comparable with levels of other ErbB growth factors, such as EGF. ${ }^{37}$ The ErbB4 receptor is present in neonatal human small intestine, including in NEC (Figure 6, B-H). Thus, the NRG4-ErbB4 signaling cascade is present in the developing intestine and may be active in breast-fed infants.

\section{Discussion}

The ErbB4 receptor tyrosine kinase is expressed in the mammalian small intestine during development, ${ }^{38}$ but to date its function has not been defined. Herein we report that NRG4, an ErbB4-specific ligand, is protective in experimental NEC. We observed protection in two different models (Figures 1, 2, and 3). Furthermore, ErbB4 is necessary for maintenance of the Paneth cell compartment and epithelial architecture in enteroid culture (Figure 4), and NRG4 blocks bacterially induced apoptosis in the small intestinal IEC-6 cell line through a Src-dependent pathway

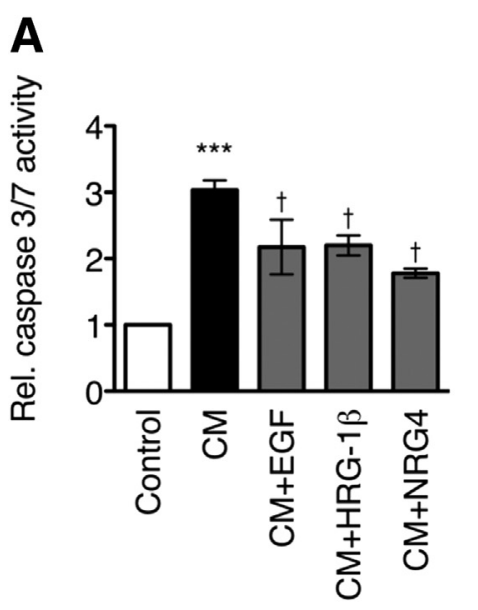

D

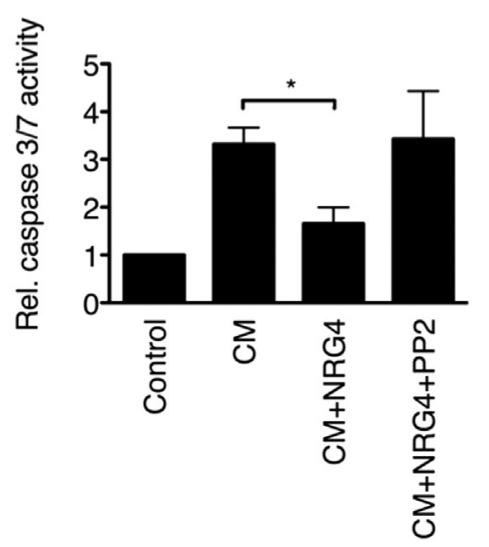

B

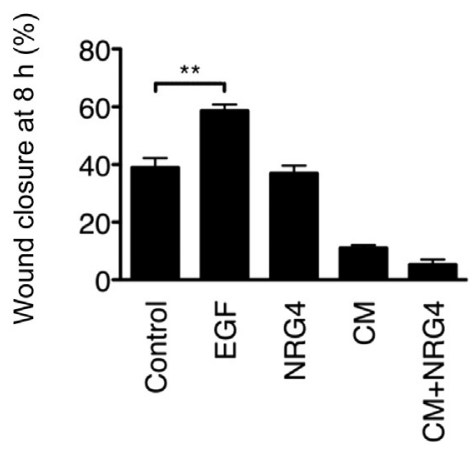

E

Figure 5 Bacterially induced small intestinal epithelial cell apoptosis is blocked by NRG4 in vitro. A: IEC-6 rat ileal epithelial cells were infected with $10^{5}$ $\mathrm{CFU} / \mathrm{mL}$ of $C$. muytjensii (CM), with or without EGF, HRG-1 3 , or NRG4; after 6 hours, apoptosis was assessed by a luminescent assay for caspase 3 and 7 activity. B: IEC-6 cells were subjected to a drill press wound assay with or without EGF, NRG4, or CM. C: Cells were treated with NRG4 or EGF for 24 hours, and EdU uptake was measured. D: One micromolar Src inhibitor PP2 reversed NRG4 protective effects on IEC-6 cell survival. All experiments included at least four independent repeats. E: Western blot analysis of the ileal mucosal scrapings from 14-day-old mice injected with varying doses of NRG4 for phospho-ErbB4 and phospho-Src. Graphs show means \pm SEM. ${ }^{*} P<0.05,{ }^{* *} P<0.01$, and ${ }^{* *} P<0.001$ versus control; ${ }^{\dagger} P<0.05$ versus CM alone. Rel., relative. 
A
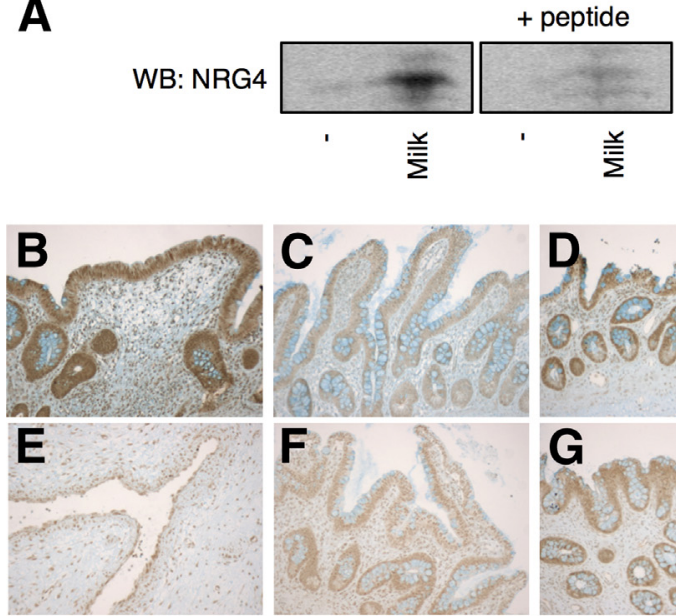

Active

NEC

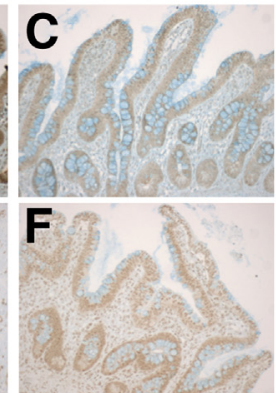

$\mathrm{Hx}$ of NEC/

stricture

H

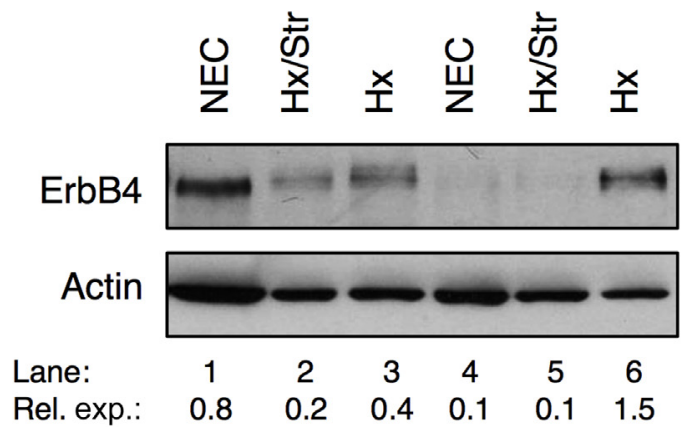

Figure 6 NRG4 is present in human milk and ErbB4 is present in human NEC intestine. A: Western blot (WB) analysis of the whey fractions of milk from anonymous donors for NRG4, with or without blocking peptide. B-H: Paraffin-embedded intestinal sections $(\mathbf{B}-\mathbf{G})$ and intestinal resection homogenates $(\mathbf{H})$ from human neonates with active disease, a history $(\mathrm{Hx})$ of NEC with ongoing complications, or a $\mathrm{Hx}$ of NEC were immunostained and immunoblotted for ErbB4. Lane 1: Ex 36 weeks' infant, 2 weeks old, active NEC; Lane 2: Ex 31 weeks' infant, 3 months old, first operation for NEC induced stricture (not active); Lane 3: Ex 27 weeks' infant, 7 months old, $\mathrm{Hx}$ of NEC, ostomy takedown (26 weeks after NEC); Lane 4: Ex 30 weeks' infant, 1 month old, active NEC; Lane 5: Ex 31 weeks' infant, 2 months old, first operation for a NEC stricture (not active); Lane 6: Ex 32 weeks' infant, 1 year old, $\mathrm{Hx}$ of NEC, ostomy takedown (12 weeks after NEC). Ex, example; Rel. exp., relative expression.

(Figure 5). Together with the observation that NRG4 is present in human milk (Figure 6), these results suggest that ErbB4 signaling has a key role in protection of the developing intestine from inflammatory insults.

Emerging evidence suggests that NRG4 expression is altered during intestinal inflammation. Studies from the Teitelbaum Lab (St. Louis, MO) showed that endogenous levels of this growth factor are reduced in a mouse model of parenteral nutrition-induced small intestinal inflammation. ${ }^{39}$ Similarly, we found loss of NRG4 in human inflammatory bowel disease and in the IL- $10^{-1-}$ mouse model of colitis. ${ }^{22}$ Thus, it is possible that the inflammatory process in NEC may decrease endogenous expression of NRG4. However, because we have shown that human breast milk contains
NRG4 (Figure 6), whereas formula does not, it is alternatively possible that the immature neonatal intestine has a low level of expression at baseline and requires an exogenous supply. Our demonstration that oral supplementation of formula with NRG4 protects against induced intestinal inflammation (Figure 1) is consistent with breast milk providing natural supplementation of NRG4 to the immature gut. Thus, infants receiving formula - which is a widely recognized risk factor for subsequent development of NEC-may be deficient in luminal NRG4. Note that in the present study we were able to analyze milk from mothers of full-term infants only. An interesting question that warrants future investigation is whether NRG4 levels (and those of other related growth factors) in milk from these mothers differ from those in milk expressed by mothers of preterm infants. For example, a study from the Ballard group in 1985 showed elevated EGF levels in preterm milk, ${ }^{40}$ underscoring the likely benefits of breast-feeding for infants at risk for disorders such as NEC. Together, these observations indicate that alterations in individual ErbB growth factor ligands can have an effect on the health of both the developing and adult gut. Further study is warranted on the regulation of, and possible replacement methods for, growth factors altered in conditions such as NEC or inflammatory bowel diseases.

In addition to detecting NRG4 in human breast milk, we also showed expression of its receptor, ErbB4, in neonatal human tissue, including infants who have, or recently had, NEC (Figure 6). Note that examination of these specimens was strictly to determine whether ErbB4 is present in neonatal intestine and NEC. We are not, with the sample size used in this study, able to draw conclusions about the relative levels of receptor expression in disease. Our interpretation of these data is thus limited to noting that ErbB4 is present in the intestinal epithelium of human neonates and that this might mean that NRG4-induced stimulation of ErbB4 is translatable from rodent models to human disease. The relative levels of this receptor in NEC and controls is the subject of ongoing investigation in our laboratory.

The data in this study are consistent with reports on the adult colon in which ErbB receptor tyrosine kinases and their cognate ligands have been clearly defined as important drivers of repair and response to inflammation. ${ }^{22,23,35,41} \mathrm{We}$ previously demonstrated that ErbB4 is induced during colonic inflammation, that its overexpression inhibits cytokine-induced apoptosis in cultured colonocytes, ${ }^{23}$ and that exogenous NRG4 protects the in vivo adult colon epithelium from cell death induced by a TNF/interferon- $\gamma$ cocktail. ${ }^{22}$ ErbB4 knockdown sensitizes human colorectal cancer cell lines to apoptosis, ${ }^{36,42}$ suggesting that an antiapoptotic role for this receptor is conserved in humans. The present results extend and expand on these observations by showing similar activity in the developing small intestine and demonstrating that orally supplied NRG4 is effective at protecting the small bowel (Figure 1).

NRG4 is a specific ErbB4 ligand that does not bind or activate other ErbB family members. ${ }^{21,22}$ Thus, selective 
activation of ErbB4 can reduce the severity of NEC in experimental rodent models. Studies from several other laboratories have shown that the specific EGFR ligand EGF $^{17,43}$ and the EGFR/ErbB4 shared ligand HB-EGF ${ }^{44,45}$ reduce the incidence and severity of experimental NEC. NRG4 selectively stimulates cell survival ${ }^{22}$ (Figure 5), whereas EGFR ligands also promote migration and proliferation $^{45}$ and modify a variety of other cellular processes, such as ion transport. ${ }^{46}$ Thus, it may be that NRG4-ErbB4 signaling is an attractive alternative candidate for the treatment of NEC or other inflammatory conditions of the intestine in that its restricted effector pathways make it less likely to exhibit the adverse effects that have been raised as concerns for EGFR activation in patients. On the other hand, increased migration and proliferation are key components of wound healing, and so it is possible that a combination of molecules targeted at multiple receptors (eg, EGF and NRG4 given together to activate EGFR and ErbB4) would provide optimal protection from NEC.

NEC in premature infants is associated with a loss of mature Paneth cells. ${ }^{3,47}$ Although Paneth cell numbers in premature infants are less than those in term infants, ${ }^{48}$ they are clearly present by 24 weeks of gestation, ${ }^{49}$ before the time at which most infants develop NEC. ${ }^{50,51}$ The data show that NRG4 preserves the Paneth cell population in adolescent mice subjected to DK NEC (Figure 3), and ErbB4 deletion reduces Paneth cell marker expression in cultured mouse ileal enteroids (Figure 4). Thus, protection of this lineage may be part of the basis for the growth factor's effects on injury in NEC. Note that the loss-of-function data (ErbB4-null enteroids) (Figure 4) must be interpreted cautiously when considering the potential effect on human disease, because available data do not point to a generalized reduction in ErbB4 levels in NEC. It is likely that altered ligand availability (eg, due to formula feeding or ongoing intestinal inflamma$\operatorname{tion}^{22,39}$ ) has a more subtle outcome than receptor deletion in the enteroid model. However, because ErbB4 knockout in the enteroids had approximately the opposite effects on Paneth cells and epithelial survival as the signaling gain-of-function (ie, ligand treatment) did in the disease models (Figures 1, 2, and 3), it seems reasonable to compare them. In addition, NRG4 has anti-apoptotic properties in enterocytes as well, both in vitro (Figure 5) and in vivo. ${ }^{22}$ It is unclear to what extent damage to undifferentiated Paneth cell precursors may affect the rat FFH model or, indeed, to what extent these cells are present in newborn rats. ${ }^{52,53}$ Thus, it is an open question whether NRG4 is selectively protecting Paneth cells or, in contrast, generally suppressing epithelial apoptosis.

The mechanisms by which ErbB4 could regulate Paneth cell survival are not well defined. ErbB4 activation in vitro promotes multiple cell survival-associated signaling cascades, including Src (Figure 5) and PI3K/Akt. ${ }^{23}$ A recent study on the balance of Paneth/goblet cells showed that mitogen-activated protein kinase signaling negatively regulates Paneth markers. ${ }^{54}$ It may be that ErbB4, which promotes Src and PI3K/Akt signaling but is not a strong mitogen-activated protein kinase stimulus, especially when NRG4 is the ligand, ${ }^{23}$ thus supports this lineage. Alternatively, regulation of the balance of Wnt signaling, which can control cell differentiation and survival in the crypt, ${ }^{55}$ may be a target of NRG4-ErbB4 activity. ErbB4 binds the Wnt regulator YAP1 and translocates to the nucleus in its company, ${ }^{56}$ and YAP1, in turn, modifies Wnt tone in the intestinal crypts. ${ }^{57}$ These alternative possibilities are currently under investigation in the laboratory. It may be that in vivo different signaling intermediates and downstream targets are required for the responses to NRG4-ErbB4 signaling in different cell types.

NEC is a highly morbid disease that can lead to multiple complications, including intestinal strictures, short gut syndrome, repeated surgeries, and extended hospital stays. Advances in understanding the growth factor signaling cascades that maintain the healthy developing intestine could lead to new methods for treating or preventing this devastating illness. In this study, we tested the effects of ErbB4 activation by NRG4 in two in vivo NEC models with distinct pathologic mechanisms and an in vitro model that has previously demonstrated relevance to the pathology of the disease. ${ }^{5,58}$ This multimodel approach is beneficial because no single model can effectively represent all facets of the human disease. We found that NRG4 was protective in each model. Furthermore, NRG4 is present in human milk (Figure 6) and is active when added to formula as a supplement (Figure 1). Together, these observations support the possibility that ErbB4 activation will be a useful therapeutic avenue for NEC and other intestinal diseases involving epithelial cell death.

\section{Acknowledgments}

We thank the members of The Saban Research Institute Gut Club for many helpful discussions and Dr. Elizabeth Pontarelli for technical assistance and advice.

S.J.M., S.L.C., H.R.F., and M.R.F. conceived and designed the experiments; S.J.M., S.L.C., J.K.B., B.A.B., L.W., M.R.F., D.A., D.A.A., and C.J.H. performed the experiments and analyzed the data; and S.J.M., C.J.H., and M.R.F. wrote the manuscript.

\section{References}

1. Hunter CJ, Upperman JS, Ford HR, Camerini V: Understanding the susceptibility of the premature infant to necrotizing enterocolitis (NEC). Pediatr Res 2008, 63:117-123

2. Emami CN, Petrosyan M, Giuliani S, Williams M, Hunter C, Prasadarao NV, Ford HR: Role of the host defense system and intestinal microbial flora in the pathogenesis of necrotizing enterocolitis. Surg Infect (Larchmt) 2009, 10:407-417

3. McElroy SJ, Underwood MA, Sherman MP: Paneth cells and necrotizing enterocolitis: a novel hypothesis for disease pathogenesis. Neonatology 2013, 103:10-20

4. Hunter CJ, Petrosyan M, Ford HR, Prasadarao NV: Enterobacter sakazakii: an emerging pathogen in infants and neonates. Surg Infect (Larchmt) 2008, 9:533-539 
5. Hunter CJ, Singamsetty VK, Chokshi NK, Boyle P, Camerini V, Grishin AV, Upperman JS, Ford HR, Prasadarao NV: Enterobacter sakazakii enhances epithelial cell injury by inducing apoptosis in a rat model of necrotizing enterocolitis. J Infect Dis 2008, 198:586-593

6. Caplan MS, Hsueh W: Necrotizing enterocolitis: role of platelet activating factor, endotoxin, and tumor necrosis factor. J Pediatr 1990, 117:S47-S51

7. Halpern MD, Clark JA, Saunders TA, Doelle SM, Hosseini DM, Stagner AM, Dvorak B: Reduction of experimental necrotizing enterocolitis with anti-TNF-alpha. Am J Physiol Gastrointest Liver Physiol 2006, 290:G757-G764

8. Seitz G, Warmann SW, Guglielmetti A, Heitmann H, Ruck P, Kreis ME, Fuchs J: Protective effect of tumor necrosis factor alpha antibody on experimental necrotizing enterocolitis in the rat. J Pediatr Surg 2005, 40:1440-1445

9. Blakely ML, Lally KP, McDonald S, Brown RL, Barnhart DC, Ricketts RR, Thompson WR, Scherer LR, Klein MD, Letton RW, Chwals WJ, Touloukian RJ, Kurkchubasche AG, Skinner MA, Moss RL, Hilfiker ML; Network NECSotNNR: Postoperative outcomes of extremely low birth-weight infants with necrotizing enterocolitis or isolated intestinal perforation: a prospective cohort study by the NICHD Neonatal Research Network. Ann Surg 2005, 241:984-989. discussion 9-94

10. Fitzgibbons SC, Ching Y, Yu D, Carpenter J, Kenny M, Weldon C, Lillehei C, Valim C, Horbar JD, Jaksic T: Mortality of necrotizing enterocolitis expressed by birth weight categories. J Pediatr Surg 2009, 44:1072-1075. discussion 5-6

11. Rowe MI, Reblock KK, Kurkchubasche AG, Healey PJ: Necrotizing enterocolitis in the extremely low birth weight infant. J Pediatr Surg 1994, 29:987-990. discussion 90-91

12. Lucas A, Cole TJ: Breast milk and neonatal necrotising enterocolitis. Lancet 1990, 336:1519-1523

13. Schanler RJ, Shulman RJ, Lau C: Feeding strategies for premature infants: beneficial outcomes of feeding fortified human milk versus preterm formula. Pediatrics 1999, 103:1150-1157

14. Warner BW: NEC, EGF, milk, and spit. Gastroenterology 2002, 123 : 383-384. discussion 4

15. Michalsky MP, Lara-Marquez M, Chun L, Besner GE: Heparinbinding EGF-like growth factor is present in human amniotic fluid and breast milk. J Pediatr Surg 2002, 37:1-6

16. Nair RR, Warner BB, Warner BW: Role of epidermal growth factor and other growth factors in the prevention of necrotizing enterocolitis. Semin Perinatol 2008, 32:107-113

17. Dvorak B, Halpern MD, Holubec H, Williams CS, McWilliam DL, Dominguez JA, Stepankova R, Payne CM, McCuskey RS: Epidermal growth factor reduces the development of necrotizing enterocolitis in a neonatal rat model. Am J Physiol Gastrointest Liver Physiol 2002, 282:G156-G164

18. Feng J, El-Assal ON, Besner GE: Heparin-binding epidermal growth factor-like growth factor reduces intestinal apoptosis in neonatal rats with necrotizing enterocolitis. J Pediatr Surg 2006, 41:742-747. discussion -7

19. Carpenter G: ErbB-4: mechanism of action and biology. Exp Cell Res 2003, 284:66-77

20. Kaushansky A, Gordus A, Budnik BA, Lane WS, Rush J, MacBeath G: System-wide investigation of ErbB4 reveals 19 sites of Tyr phosphorylation that are unusually selective in their recruitment properties. Chem Biol 2008, 15:808-817

21. Harari D, Tzahar E, Romano J, Shelly M, Pierce JH, Andrews GC, Yarden Y: Neuregulin-4: a novel growth factor that acts through the ErbB-4 receptor tyrosine kinase. Oncogene 1999, 18:2681-2689

22. Bernard JK, McCann SP, Bhardwaj V, Washington MK, Frey MR: Neuregulin-4 is a survival factor for colon epithelial cells both in culture and in vivo. J Biol Chem 2012, 287:39850-39858

23. Frey MR, Edelblum KL, Mullane MT, Liang D, Polk DB: The ErbB4 growth factor receptor is required for colon epithelial cell survival in the presence of TNF. Gastroenterology 2009, 136:217-226
24. Hilliard VC, Frey MR, Dempsey PJ, Peek RM Jr, Polk DB: TNFalpha converting enzyme-mediated ErbB4 transactivation by TNF promotes colonic epithelial cell survival. Am J Physiol Gastrointest Liver Physiol 2011, 301:G338-G346

25. Committee for the Update of the Guide for the Care and Use of Laboratory Animals; National Research Council: Guide for the Care and Use of Laboratory Animals: Eighth Edition. Washington, DC, National Academies Press, 2011

26. Nadler EP, Dickinson E, Knisely A, Zhang XR, Boyle P, BeerStolz D, Watkins SC, Ford HR: Expression of inducible nitric oxide synthase and interleukin-12 in experimental necrotizing enterocolitis. J Surg Res 2000, 92:71-77

27. Zhang C, Sherman MP, Prince LS, Bader D, Weitkamp JH, Slaughter JC, McElroy SJ: Paneth cell ablation in the presence of Klebsiella pneumoniae induces necrotizing enterocolitis (NEC)-like injury in the small intestine of immature mice. Dis Model Mech 2012, 5:522-532

28. Sawada M, Takahashi K, Sawada S, Midorikawa O: Selective killing of Paneth cells by intravenous administration of dithizone in rats. Int J Exp Pathol 1991, 72:407-421

29. Long W, Wagner KU, Lloyd KC, Binart N, Shillingford JM, Hennighausen L, Jones FE: Impaired differentiation and lactational failure of Erbb4-deficient mammary glands identify ERBB4 as an obligate mediator of STAT5. Development 2003, 130:5257-5268

30. Sato T, Stange DE, Ferrante M, Vries RG, Van Es JH, Van den Brink S, Van Houdt WJ, Pronk A, Van Gorp J, Siersema PD, Clevers H: Long-term expansion of epithelial organoids from human colon, adenoma, adenocarcinoma, and Barrett's epithelium. Gastroenterology 2011, 141:1762-1772

31. Iversen C, Mullane N, McCardell B, Tall BD, Lehner A, Fanning S, Stephan R, Joosten H: Cronobacter gen. nov., a new genus to accommodate the biogroups of Enterobacter sakazakii, and proposal of Cronobacter sakazakii gen. nov., comb. nov., Cronobacter malonaticus sp. nov., Cronobacter turicensis sp. nov., Cronobacter muytjensii sp. nov., Cronobacter dublinensis sp. nov., Cronobacter genomospecies 1 , and of three subspecies, Cronobacter dublinensis subsp. dublinensis subsp. nov., Cronobacter dublinensis subsp. lausannensis subsp. nov. and Cronobacter dublinensis subsp. lactaridi subsp. nov. Int J Syst Evol Microbiol 2008, 58:1442-1447

32. Sato T, Vries RG, Snippert HJ, van de Wetering M, Barker N, Stange DE, van Es JH, Abo A, Kujala P, Peters PJ, Clevers H: Single Lgr5 stem cells build crypt-villus structures in vitro without a mesenchymal niche. Nature 2009, 459:262-265

33. Yan F, Cao H, Cover TL, Washington MK, Shi Y, Liu L, Chaturvedi R, Peek RM Jr, Wilson KT, Polk DB: Colon-specific delivery of a probiotic-derived soluble protein ameliorates intestinal inflammation in mice through an EGFR-dependent mechanism. J Clin Invest 2011, 121:2242-2253

34. Zhang Y, Dube PE, Washington MK, Yan F, Polk DB: ErbB2 and ErbB3 regulate recovery from dextran sulfate sodium-induced colitis by promoting mouse colon epithelial cell survival. Lab Invest 2012, 92:437-450

35. Yamaoka T, Yan F, Cao H, Hobbs SS, Dise RS, Tong W, Polk DB: Transactivation of EGF receptor and ErbB2 protects intestinal epithelial cells from TNF-induced apoptosis. Proc Natl Acad Sci U S A 2008, 105:11772-11777

36. Frey MR, Hilliard VC, Mullane MT, Polk DB: ErbB4 promotes cyclooxygenase-2 expression and cell survival in colon epithelial cells. Lab Invest 2010, 90:1415-1424

37. Dvorak B, Fituch CC, Williams CS, Hurst NM, Schanler RJ: Increased epidermal growth factor levels in human milk of mothers with extremely premature infants. Pediatr Res 2003, 54:15-19

38. Srinivasan R, Poulsom R, Hurst HC, Gullick WJ: Expression of the c-erbB-4/HER4 protein and mRNA in normal human fetal and adult tissues and in a survey of nine solid tumour types. J Pathol 1998, 185: 236-245

39. Feng Y, Teitelbaum DH: Epidermal growth factor/TNF-alpha transactivation modulates epithelial cell proliferation and apoptosis in a 
mouse model of parenteral nutrition. Am J Physiol Gastrointest Liver Physiol 2012, 302:G236-G249

40. Read LC, Francis GL, Wallace JC, Ballard FJ: Growth factor concentrations and growth-promoting activity in human milk following premature birth. J Dev Physiol 1985, 7:135-145

41. Yamaoka T, Frey MR, Dise RS, Bernard JK, Polk DB: Specific epidermal growth factor receptor autophosphorylation sites promote mouse colon epithelial cell chemotaxis and restitution. Am J Physiol Gastrointest Liver Physiol 2011, 301:G368-G376

42. Lee D, Yu M, Lee E, Kim H, Yang Y, Kim K, Pannicia C, Kurie JM, Threadgill DW: Tumor-specific apoptosis caused by deletion of the ERBB3 pseudo-kinase in mouse intestinal epithelium. J Clin Invest 2009, 119:2702-2713

43. Clark JA, Lane RH, Maclennan NK, Holubec H, Dvorakova K, Halpern MD, Williams CS, Payne CM, Dvorak B: Epidermal growth factor reduces intestinal apoptosis in an experimental model of necrotizing enterocolitis. Am J Physiol Gastrointest Liver Physiol 2005, 288:G755-G762

44. Radulescu A, Zhang HY, Yu X, Olson JK, Darbyshire AK, Chen Y, Besner GE: Heparin-binding epidermal growth factor-like growth factor overexpression in transgenic mice increases resistance to necrotizing enterocolitis. J Pediatr Surg 2010, 45:1933-1939

45. Feng J, Besner GE: Heparin-binding epidermal growth factor-like growth factor promotes enterocyte migration and proliferation in neonatal rats with necrotizing enterocolitis. J Pediatr Surg 2007, 42: 214-220

46. McCole DF, Keely SJ, Coffey RJ, Barrett KE: Transactivation of the epidermal growth factor receptor in colonic epithelial cells by carbachol requires extracellular release of transforming growth factoralpha. J Biol Chem 2002, 277:42603-42612

47. Coutinho HB, da Mota HC, Coutinho VB, Robalinho TI, Furtado AF, Walker E, King G, Mahida YR, Sewell HF, Wakelin D: Absence of lysozyme (muramidase) in the intestinal Paneth cells of newborn infants with necrotising enterocolitis. J Clin Pathol 1998, 51:512-514

48. Salzman NH, Polin RA, Harris MC, Ruchelli E, Hebra A, ZirinButler S, Jawad A, Martin Porter E, Bevins CL: Enteric defensin expression in necrotizing enterocolitis. Pediatr Res 1998, 44:20-26
49. Mallow EB, Harris A, Salzman N, Russell JP, DeBerardinis RJ, Ruchelli E, Bevins CL: Human enteric defensins. gene structure and developmental expression. J Biol Chem 1996, 271:4038-4045

50. Neu J, Walker WA: Necrotizing enterocolitis. N Eng1 J Med 2011, 364:255-264

51. Yee WH, Soraisham AS, Shah VS, Aziz K, Yoon W, Lee SK; Canadian Neonatal Network: Incidence and timing of presentation of necrotizing enterocolitis in preterm infants. Pediatrics 2012, 129: e298-e304

52. Chen CL, Yu X, James IO, Zhang HY, Yang J, Radulescu A, Zhou Y, Besner GE: Heparin-binding EGF-like growth factor protects intestinal stem cells from injury in a rat model of necrotizing enterocolitis. Lab Invest 2012, 92:331-344

53. Sherman MP, Bennett SH, Hwang FF, Sherman J, Bevins CL: Paneth cells and antibacterial host defense in neonatal small intestine. Infect Immun 2005, 73:6143-6146

54. Heuberger J, Kosel F, Qi J, Grossmann KS, Rajewsky K, Birchmeier W: Shp2/MAPK signaling controls goblet/paneth cell fate decisions in the intestine. Proc Natl Acad Sci U S A 2014, 111: 3472-3477

55. Farin HF, Van Es JH, Clevers H: Redundant sources of Wnt regulate intestinal stem cells and promote formation of Paneth cells. Gastroenterology 2012, 143:1518-1529. e7

56. Komuro A, Nagai M, Navin NE, Sudol M: WW domain-containing protein YAP associates with ErbB-4 and acts as a co-transcriptional activator for the carboxyl-terminal fragment of ErbB-4 that translocates to the nucleus. J Biol Chem 2003, 278:33334-33341

57. Barry ER, Morikawa T, Butler BL, Shrestha K, de la Rosa R, Yan KS, Fuchs CS, Magness ST, Smits R, Ogino S, Kuo CJ, Camargo FD: Restriction of intestinal stem cell expansion and the regenerative response by YAP. Nature 2013, 493:106-110

58. Hunter CJ, Williams M, Petrosyan M, Guner Y, Mittal R, Mock D, Upperman JS, Ford HR, Prasadarao NV: Lactobacillus bulgaricus prevents intestinal epithelial cell injury caused by Enterobacter sakazakii-induced nitric oxide both in vitro and in the newborn rat model of necrotizing enterocolitis. Infect Immun 2009, 77: $1031-1043$ 